\title{
K-WIRE AND SCREW FIXATION OF LATERAL END CLAVICLE FRACTURES
}

\author{
Amber Varyani ${ }^{1}$
}

${ }^{1}$ Assistant Professor, Department of Orthopaedics, Government Medical College, Kannauj.

\section{ABSTRACT}

\section{BACKGROUND}

As a known fact, lateral end clavicle fractures are difficult to treat conservatively. Till date various methods of stabilisation of the displaced lateral end factures are in use. Method, which is less invasive and has minimal complication was used to fix these fractures in our study.

\section{MATERIALS AND METHODS}

Study was conducted in Ortho Department, G. M. C., Kannauj; 20 lateral end clavicle type 2 fractures were included. All type 2 lateral end clavicle displaced fractures were included. Fractures were reduced with a small anterosuperior incision. Fractures were fixed by K-wires followed by coracoclavicular screw. Arm was supported in an arm pouch for six weeks. The routine removal of Kwire was performed in six weeks at 0. P. D. Clinicoradiological results were studied after six weeks and monthly interval and thereafter until union.

\section{RESULTS}

All 20 fractures were united. There was no loss of reduction even after removal of Kirschner wires at six weeks. The mean average time of union was 9.5 weeks with an SD of 3.5. Patients regained near normal range of motion and the mean average constant score at the end of one year was 98.37 with an SD of 2.87. The range of motion remained the same in those who were followed up. Infection and Kirschner wire breakage were not noted in our series.

\section{CONCLUSION}

The clinicoradiological outcome were encouraging and comparable with earlier studies.

\section{KEYWORDS}

K-Wire - Kirschner Wire, Cancellous Screw.

HOW TO CITE THIS ARTICLE: Varyani A. K-wire and screw fixation of lateral end clavicle fractures. J. Evolution Med. Dent. Sci. 2016;5(91):6765-6768, DOI: 10.14260/jemds/2016/1528

\section{BACKGROUND}

Even in today's scenario clavicle end fractures are approached and dispensed with conservative treatment, but lateral end clavicle fracture with displaced nature are complicated and need surgical intervention with special attention. Distal clavicle fractures account for $15 \%$ of all clavicle fractures. NEER classified this fracture into two types based on the condition of Coracoclavicular (CC) ligament. ${ }^{(1,2)}$

Type 1 - Minimally displaced fractures that occur lateral to the CC ligament. Type 2 - Displaced fractures that the proximal fragment is detached from the CC ligament.

The type 1 fracture is a stable kind of injury with an intact CC ligament, which prevents the fragments from substantial displacement. In type 2 fractures, the distal clavicle fragment suffers the distal pull by the weight of the arm and medial pull by the pectorii muscles and also the latissimus dorsi muscle, while the proximal fragment is pulled posteriorly by the trapezius. Due to these forces, fracture is highly displaced and unstable in nature.

Financial or Other, Competing Interest: None.

Submission 21-09-2016, Peer Review 01-11-2016,

Acceptance 07-11-2016, Published 14-11-2016.

Corresponding Author:

Dr. Amber Varyani,

117/H-1/267,

Model Town, Pandunagar,

Kanpur, Uttar Pradesh.

E-mail: amber_varyani2000@yahoo.com

DOI: $10.14260 /$ jemds/2016/1528
The type 2 fracture is further divided into type 2-A in which fracture occurs medial to CC ligament and type 2-B in which fracture occurs more lateral with CC ligament, disrupted from proximal fragment. With addition of more sub types, the NEER classification of distal clavicle fracture was later compiled to include up to five types.

Type 3 - Fracture extends into Acromioclavicular Joint (ACJ).

Type 4 - Fracture with periosteal disruption occurring in children.

Type 5 - Avulsion fracture of distal clavicle with the smaller cortical fragment remains attached to the CC ligament.

As per finding, the displaced type 2 fracture treated conservatively resulted in $30 \%$ of non-union and remaining in either bony union or fibrous union. Such a high percentage of non-union advocates for operative fixation.(3)

Though the best and ideal method for internal fixation is a matter of non-yielding debate, but a few series of coracoclavicular screws, tension band, K-wire hook plates, special anatomical locking and non-locking plates have been published with encouraging results in all the series.

\section{Radiological Evaluation}

In significant fracture displacement, the skin may suffer too much tension by bone spike of proximal fragment that requires urgent focus. In case of high energy trauma such as road side accidents, a meticulous examination is required to exclude other associated injuries. Neck and head injury are 
noted in upto $10 \%$ cases, while ipsilateral rib fracture and associated chest injuries are also often noted.

A shoulder trauma series including AP view, scapulary view and axillary view of injured shoulder should be the standard radiographic investigation. Fracture could be classified on the basis of fracture displacement. An axillary view is useful in correspondence with AP view of the fracture. CT scan is sometimes needed in the case of complex and comminuted fracture patterns. Ultrasound and M.R.I. are seldom necessary except associated soft tissue injuries, such as a rotator cuff tear is suspected.

Conservative management tell us that there is no doubt that the initial treatment for type 1 and type 3 fractures will be non-operative. An arm sling is offered to support the weight of arm. Pendulum exercises can be started as soon as pain can be tolerated. The arm sling could be taken off when the pain has abated with active assisted and passive mobilisation exercises to start shortly. Strengthening exercises can be started when a pain free full shoulder range of motion achieved. $(3,4)$

Despite the excellent prognosis of type 1 and type 3 fractures, patients should be informed regarding the decimated chances of late residual shoulder symptoms, viz. ACJ arthrosis. For those patients who have substantial residual symptoms, operative treatment with distal clavicle resection may be needed to alleviate the symptoms.

\section{Surgical Management available for Distal End Clavicle Fracture}

Management of type 2 fractures is always the center of debate. With high risk of non-union, some surgeons will advise operative treatment for all type of type 2 fractures, while the advocates of non-operative treatment argue that most of these non-unions are asymptomatic but the patients having substantial fracture displacement, open wound and overlying skin compromises are clear indication of surgery; others may go for conservative treatment. $(5,6)$

When a non-operative treatment is selected, patients should be carefully consulted and informed about the following.

- The average risk of non-union is $30 \%$.

- Most distal clavicle fracture non-unions will end up with mild symptoms and functional loss is usually low.

- The patients who develop symptomatic non-unions, late reconstructive surgery becomes inevitable.

Hence, making a judgment from the above each and every patient having type 2 fracture should be considered individually. For a low age, young and active patients who cannot take a risk of late reconstruction surgery shall have operative treatment early. On the opposite, the patients who have multiple medical co-morbidities with high perioperative risk or are immunocompromised shall go for initial conservative treatment.

Though there are numerous operative techniques reported in the past, but on a whole methods of surgical treatment can be summarised as below.

- Transacromial or intramedullary fixation in terms of Kwires and different pins such as the Steinmann pin, Knowles pin, etc. This fixation could be strengthened further by concomitant tension band wires.

- Coracoclavicular indirect fixation with use of screw, suture anchor, Dacron graft or Mersilene tape.
- Open reduction and clavicular plate fixation with the use of different plate systems such as Basler plate, AO hook plate, Wolter hook plate, etc.

Different surgical techniques have their own advantages and disadvantages (Picture: 1). With more than 20 techniques described so far, no single fixation is ideal and perfect. There is no such method of fixation that could be said unanimously the best surgical method to fix these fractures. Whichever method is chosen, careful planning and familiarity with the features of that operative technique are basic requirement for the best clinical outcome. $(7,8)$

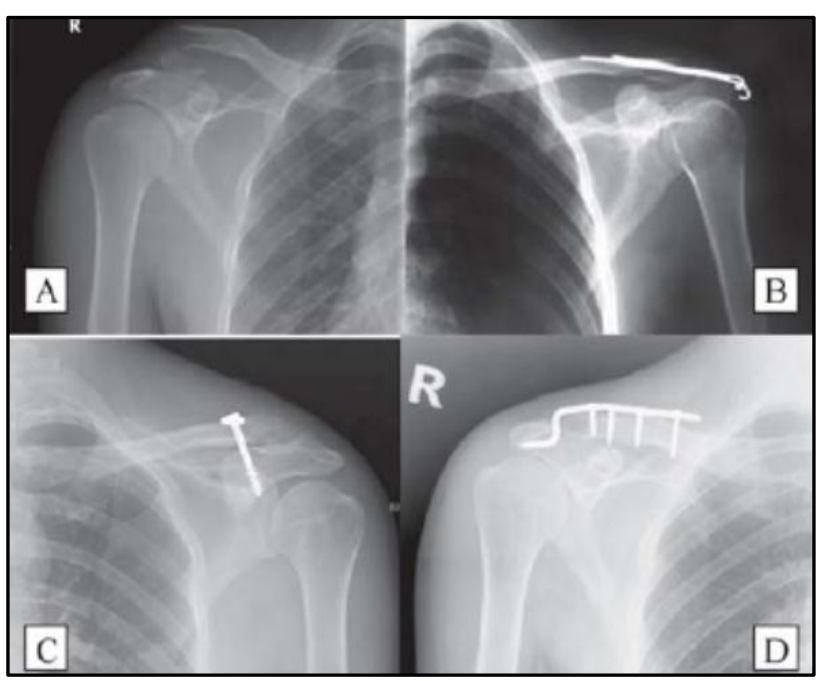

Picture 1. Showing Different Methods of Fixation

\section{Patients and Methods}

This prospective study was conducted at Government Medical College, Kannauj, 2016.

\section{Inclusion Criteria}

1. NEER Type - II displaced fractures of lateral end clavicle.

2. Medically fit patients.

A brief incision of $5-8 \mathrm{~cm}$ with center over fracture site is made antero-superiorly. Fracture site is reached by cautery dissection. Special care is taken to make sure that acromioclavicular ligaments are not disturbed. The fracture is reduced with the help of a clamp and fixed with two $1.8 \mathrm{~mm}$ transacromial $\mathrm{K}$-wire and reduction is monitored on an image intensifier. After the desired reduction is achieved, a hole of $3.2 \mathrm{~mm}$ is drilled centrally through clavicle into the coracoids and a $4 \mathrm{~mm}$ cancellous screw is fixed. From the third post-op day, the pendulum exercises are started. From $7^{\text {th }}$ post-op day, the passive flexion and extension is started. On $14^{\text {th }}$ postop day, the sutures are removed and gradual abduction is started. K-wire removal is done on $6^{\text {th }}$ post-op week in outpatient department under local anaesthesia; an active shoulder movement is allowed. The clinicoradiological followup to confirm union is done on $6^{\text {th }}$ post-op week and at monthly interval and a $6^{\text {th }}$ monthly evaluation is done after the union was confirmed. The union is confirmed with 2 radiographs, viz. anteroposterior and axillary view of shoulder. The cortical continuity, static fracture line gap, reconstitution of medullary cavity, in consecutive radiographs and hard fracture site were clinical evidences of union at fracture site. $(9,10,11,12)$ 


\section{RESULTS}

Only in single case, the K-wire got loosened and migrated from its place prior six weeks, but reduction remained unaltered. Infection and non-healing wounds were not reported in our series. Skin impingement was noted in 2 of our cases due to bent $\mathrm{K}$-wire. As the clinicoradiological union was confirmed, the patients were allowed to return to sporting activities.(13,14)

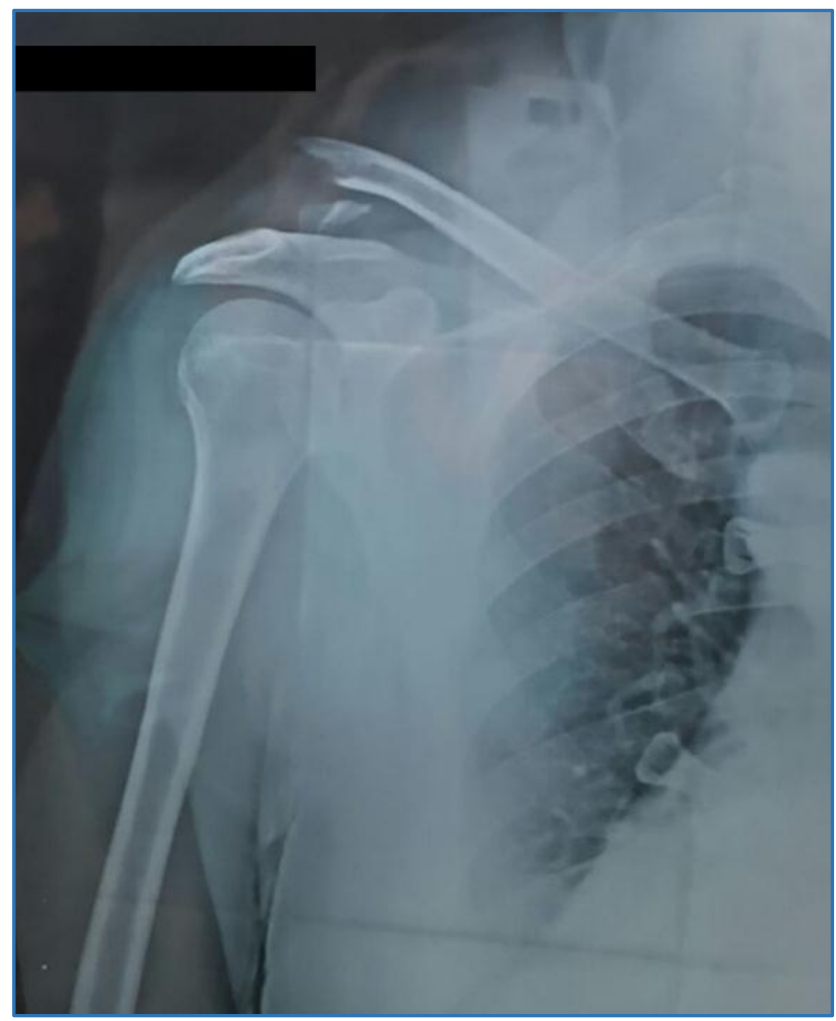

Picture 2. Showing Type 2 Lateral End Clavicle Fracture

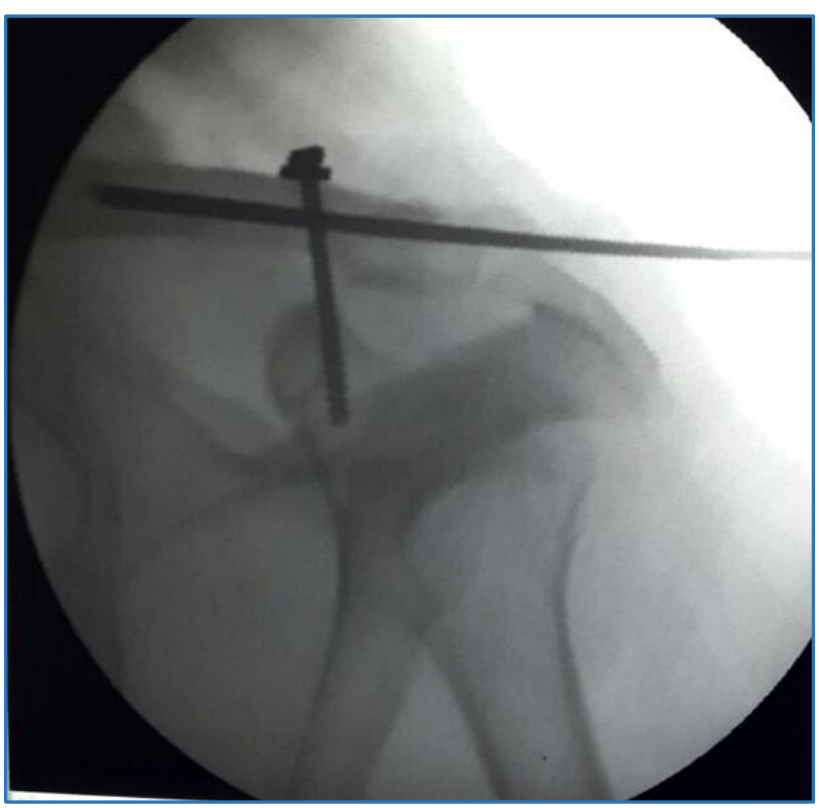

Picture 3. Showing K-Wire and Screw Fixation in Lateral End Clavicle Fracture

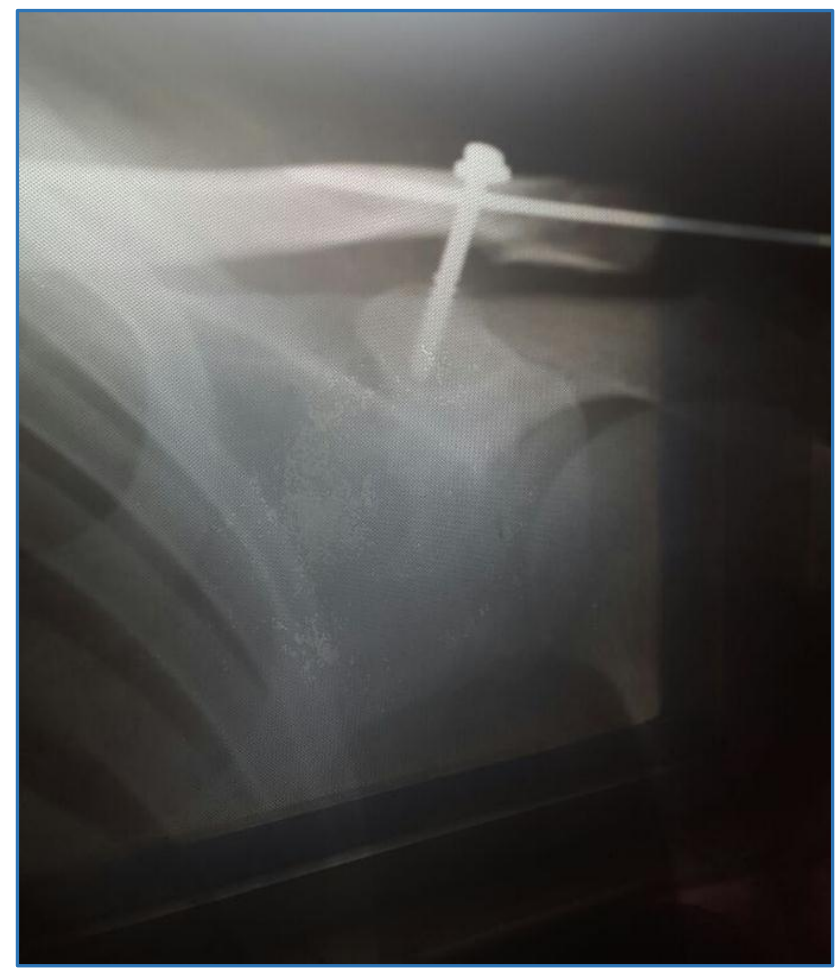

Picture 4. Showing Pin and Screw Fixation in Lateral End Clavicle Fracture

\section{DISCUSSION}

Fracture of distal clavicle is less frequent than the more common middle-third fracture. Type 2 displaced fracture of distal end clavicle have extremely high rate of delayed union and non-union. The reason for the same is the rotational movement that occurs at the acromioclavicular joint, gets transferred to the fracture site which provides mobility to the lateral end resulting in the non-union. On the other hand rigid internal fixation between clavicle and acromion will fail, as it interferes with the routine rotational movement of the clavicle with respect to coracoid and acromion. Furthermore, if fracture unites with this kind of fixation, the first compulsion is removal of implant before full mobilisation is started. Such implant retrieval operation requires comprehensive exposure and substantial soft tissue damage is involved along with the risk of neurovascular injury.(15,16)

Our method is minimally invasive. The routine removal of $\mathrm{K}$-wires before active mobilisation of shoulder decimates the complication of partially rigid kind of fixation and fracture reduction is maintained. The fracture becomes sticky at the $7_{\text {th }}$ week; the ossification is of intramembranous nature; the union shall occur if conducive environment is provided. A single plain radiographic evaluation may give sign of delayed union, but we recommend two plain radiographic evaluations to confirm union, viz. anterosuperior and axillary view, since in some cases fracture line is visible in anterosuperior view but cortical continuity in axillary view confirms union. Furthermore, reformed medullary cavity, static fracture line gap and substantially hard fracture site suggests for fracture union. We recommend CT scan in cases where evaluation of union is doubtful, but routine use of CT scan to confirm union is not suggested. 
Transacromial K-wires are passed under $\mathrm{C}$-arm guidance to hold the fracture in anatomical position and $4.0 \mathrm{~mm}$ cancellous screw is fixed through clavicle into the coracoids. $\mathrm{K}$-wires and screw are removed in O.P.D. under local anaesthesia. The limb is kept supported in an arm pouch for six weeks to make patient conscious that their shoulder needs protection and secondly the stress exerted by hanging limb is guarded fact minimises undue stress on the healing bone. The results of our technique of fixation are highly inspiring and encouraging with this small group of 20 patients and comparable with other studies.

Neer reported $100 \%$ union with Kirschner wire fixation and suggested displaced fracture should be stabilised for better results. Kona et al reported 52.6 success rate with Kirschner wires. Eskola et al reported 95.6 success rate with two Kirschner wires. Loosening of Kirschner wires, migration, undue stress during active mobilisation, back out and breakage are known complications with Kirschner wires fixation. We addressed a few of such complications by removing Kirschner wires before active mobilisation. Even after removal of Kirschner wires, reduction is maintained by figure-eight suture.

Edward et al, Yamaguchi et al and Ballmer et al reported $100 \%$ success rate in their series with Bosworth coracoclavicular fixation.

Coracoclavicular reconstruction using a Dacron graft has yielded $100 \%$ success rate in a series by Goldberg et al. However, the nature of surgical dissection is more traumatic than other minimally invasive techniques. Levy described single figure-eight suture fixation with PDS suture with a success rate of $100 \%$.

\section{CONCLUSION}

Our method of fixation allows stable fixation with K-wires and cancellous screw. K-wire allows active mobilisation and decimates the number of implant related complications.

Although, the result of our studies over 20 patients are inspiring and encouraging, but we need to further extend the study on larger counts of patients to prove the superior role of our method on type 2 displaced clavicle end fracture.

\section{REFERENCES}

1. Neer CS. Fractures of distal third of the clavicle. Clin Orthop Relat Res 1968;58:43-50.

2. Robinson CM, Cairns DA. Primary nonoperative treatment of displaced lateral fractures of the clavicle. J Bone Joint Surg Am 2004;86-A(4):778-82.
3. Neviaser JS. The treatment of fractures of the clavicle. Surg Ciln North Am 1963;43:1555-63.

4. Zenni EJ, Krieg JK, Roesn MJ. Open reduction and internal of clavicular fractures. J Bone Joint Surg Am 1981;63(1):147-51.

5. Eskola A, Vainionpaa S, Patiala $\mathrm{H}$, et al. Outcome of operative treatment if fresh lateral clavicular fracture. Ann Chir Gynaecol 1987;76(3):167-9.

6. Robinson CM, Court-Brown CM, McQueen MM, et al. Estimating the risk of non-union following non-operative treatment of a clavicular fracture. J Bone Joint Surg Am 2004;86-A(7):1359-65.

7. Ballmer FT, Gerber C. Coracoclavicular screwfixation for unstable fractures of the distal clavicle. A report of five cases. J Bone Joint Surg Br 1991;73-B:291-4.

8. Macheras G, Kateros KT, Savvidou OD, et al Coracoclavicular screw fixation for unstable distal clavicle fractures. Orthopedics 2005;28(7):693-6.

9. Yamaguchi H, Arakawa H, Kobayashi M. Results of the Bosworth method for unstable fractures of the distal clavicle. Int Orthop 1998;22(6):366-8.

10. Bezer M, Aydin N, Guven 0. The treatment of distal clavicle fractures with coracoclavicular ligament disruption: a report of 10 cases. J Orthop Trauma 2005;19(8):524-8.

11. Chen $\mathrm{CH}$, Chen WJ, Shih CH. Surgical treatment for distal clavicle fracture with coracoclavicular ligament disruption. J Trauma 2002;52(1):72-8.

12. Shin SJ, Roh KJ, Kim JO, et al. Treatment of unstable distal clavicle fractures using two suture anchors and suture tension bands. Injury 2009;40(12):1308-12.

13. Kona J, Bosse MJ, Staeheli JW, et al. Type IT distal clavicle fractures: a retrospective review of surgical treatment. J Orthop Trauma 1990;4(2):115-20.

14. Haidar SG, Krishnan KM, Deshmukh SC. Hookplate fixation for type II fractures of the lateral endof the clavicle. J Shoulder Elbow Surg 2006;15(4):419-23.

15. Klein SM, Badman Bl, Keating CJ, et al. Results of surgical treatment for unstable distal clavicular fractures. J Shoulder Elbow Surg 2010;19(7):1049-55.

16. Herrmann S, Schmidmaier G, Greiner S. Stabilisation of vertical unstable distal clavicular fractures (Neer 2b) using locking T-plates and suture anchors. Injury 2009;40(3):236-9. 